\title{
Modular microsystem for epithelial cell culture and electrical characterisation $^{\text {th }}$
}

\author{
S. Hediger ${ }^{\mathrm{a}, *}$, A. Sayah ${ }^{\text {a, }}$ J.D. Horisberger ${ }^{\mathrm{b}}$, M.A.M. Gijs ${ }^{\text {a }}$ \\ a Institute of Microsystems, Swiss Federal Institute of Technology Lausanne, CH-1015 Lausanne EPFL, Switzerland \\ ${ }^{\mathrm{b}}$ Institute of Pharmacology and Toxicology, University of Lausanne, CH-1005 Lausanne UNIL, Switzerland
}

Received 19 May 2000; received in revised form 11 April 2001; accepted 19 April 2001

\begin{abstract}
We have realised a microsystem for the culture and electrical characterisation of epithelial cell layers for cell-based diagnostic applications. The main goal of this work is to achieve both cell culture and impedimetric and potentiometric characterisation on a single device. The miniaturised cell culture system enables the uses of scarce epithelial cells, as obtained from transgenic mice or from human biopsies. The device is completely modular and offers high flexibility: a polycarbonate membrane used as cell substrate is glued in between two moulded Polydimethylsiloxane (PDMS) layers to form a sandwich, which is placed between two stacks, containing the microfluidic channels and integrated measurement electrodes. The polycarbonate membrane sandwich can be removed, replaced or analysed at any time. We have characterised the impedimetric properties of our microsystem, demonstrated epithelial cell layer growth within it, and have done the initial electrical characterisation of epithelial cell layers. (C) 2001 Elsevier Science B.V. All rights reserved.
\end{abstract}

Keywords: Epithelial cell; Biological microsystem; Micromachining; Powder blasting; Cell culture; Electrical resistance

\section{Introduction}

Miniaturised bio-chemical and cell-based measurement systems will have a large impact on the way medical diagnostics will be done in the near future. More particularly, in the field of clinical diagnostics and pharmacology, the use of living cells for fast specific and non-specific chemical sensing is an area of increasing importance (Fuhr, 1996; Fuhr and Shirley, 1995; Standen et al., 1987). A cell or cell layer is a complex system with appropriate response to a variety of external physical and chemical excitations. Experiments on such living biological systems [for example using electrical resistance or fluorescence measurements (Hediger et al., 1999, 2000; Grimmes and Martinsen, 2000)] can lead to the study of diffusion and transport of biological or pharmacological molecules through the cell or cell layer (Misfeldt et al., 1976; Milks et al.,

\footnotetext{
Editors Selection

* Corresponding author. Tel.: + 41-21-693-6585; fax: + 41-21-6935950 .

E-mail address: serge.hediger@epfl.ch (S. Hediger).
}

1983). In general, all these experiments are done in macroscopic tissue resistance measurement chambers ${\text { (Corning } \text { Costar }^{\circledR}, 1999 \text {; Falcon }}^{\circledR}$, 1998), with a diameter ranging from a few millimetres up to some centimetres. In these devices, a cell tissue layer is grown on a nano-porous membrane placed at the bottom of the chamber and measured with two pairs of electrodes, which are mechanically inserted in the system after cell culture. The progress in three-dimensional microfabrication technology has opened new possibilities for miniaturising these epithelial cell culture and analysis devices. Miniaturisation offers high potential for both fundamental research and clinical diagnostics. In recent work, the potential of miniaturised systems for the non-invasive analysis of cells has been well exploited in devices such as the PhysioControl-Microsystem $\left(\mathrm{PCM}^{\circledR}\right)$ (Wolf et al., 1998; Ehret et al., 1998). In this miniaturised device, cell parameters such as growth and viability or extracellular acidification and respiration rates can be monitored in a continuous way.

The aim of our device is to enable epithelial cell layer culture on small $\left(1 \mathrm{~mm}^{2}\right)$ surfaces and to characterise 
the ionic transport properties of such cell layers, more specifically the Na transport through the epithelial cell $\mathrm{Na}^{+}$channel (Mall et al., 2000). When biological tissues to be tested are scarce, for example in the case of cell cultures from transgenic mice or from biopsies taken from patients (Mall et al., 2000), there is a tremendous advantage in having a cell culture minichamber, which permits physiological measurements on epithelial cell surfaces of the order of $1 \mathrm{~mm}^{2}$ or smaller. Our system is with integrated electrical electrodes, micro-fluidic channels and feed-throughs, making it extremely compact. Moreover we have chosen a modular set-up, in which the cell culture membranes can be reversibly placed within or removed from the system, thereby offering flexibility and economic interest.

In this paper, we present this modular option [an integrated disposable device has been presented previously (Hediger et al., 2000)] for the realisation of miniaturised cell culture applications. The substrate chosen for the cell layer growth is a nano-porous polycarbonate membrane, as used for macroscopic cell tissue cul-

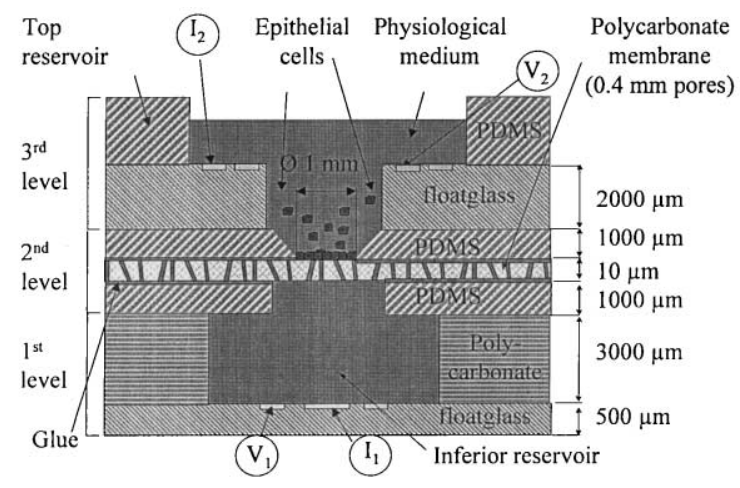

Fig. 1. Schematic cross-section of the modular tissue measurement structure showing the PDMS sandwiched nano-porous membrane, assembled with top and bottom microfluidic reservoirs. The three different levels are detachable and mechanically pressed together during the cell culture and electrical characterisation experiments.

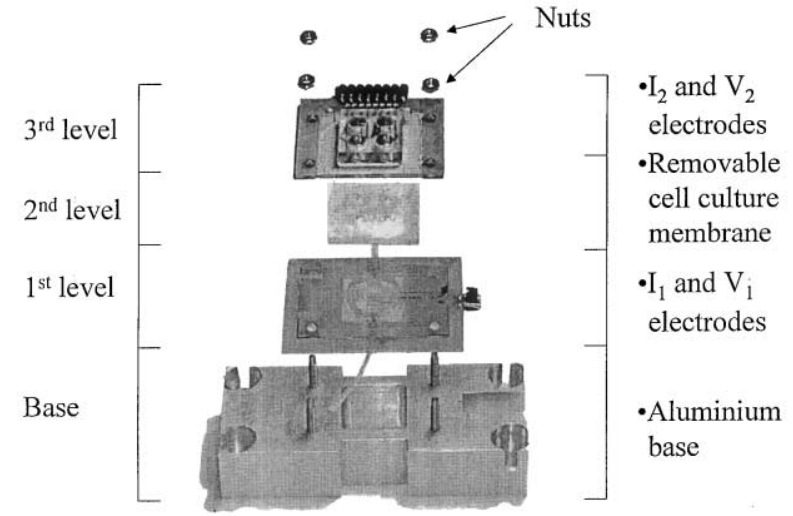

Fig. 3. Optical photograph mounting showing schematically the different levels of the modular tissue culture device and the attachment by mechanical pressing on an Al base block.

ture and measurements. In this modular device, micro-fluidic channels and electrical contacts can be reversibly assembled with the cell culture membrane. This approach allows re-use of the micro-fluidic and electrode patterns, when changing the culture membrane, and the use of the separated membrane for a different type of analysis. The structure facilitates control of the cell layer growth, the measurement of the cell layer resistance, the transport and diffusion of biological or pharmacological molecules through the cell layer and accurate measurement of (bio-)chemically induced resistance variations. We have realised this microsystem using photolithography, various etching procedures [among which powder-blasting (Belloy et al., 2000b,a)], thin film deposition, and gluing technologies. Also, we have compared the efficiency of different electrode materials, like $\mathrm{Pt}, \mathrm{Ag}$ and $\mathrm{Ag} / \mathrm{AgCl}$. Finally we have cultured layers of mCCD cells (cortical collecting tact cells) of transgenic mice on our devices and have measured the evolution in time of transepithelial resistance Rte and voltage Vte.

\section{Design}

The main parts of the modular tissue measurement device are the polycarbonate porous membrane for the support of the cell culture, fluidic access structures to the membrane and a four-point impedance and voltage probe set-up integrated within the device. We use Ag electrodes for the injection of current $\left(I_{1}\right.$ and $\left.I_{2}\right)$ and $\mathrm{Ag} / \mathrm{AgCl}$ electrodes for the voltage measurements (Grimmes and Martinsen, 2000). Fig. 1 shows a schematic cross-section of the basic modular tissue measurement structure: it consists of an assembly of three different stacks. The first level is a glued assembly of a floatglass wafer and a machined $2 \mathrm{~mm}$ thick polycarbonate plate. Micro-patterned electrodes are previously deposited on the floatglass wafer, namely the lower

Fig. 2. Schematic diagram of the batch process for the realisation of the modular tissue culture device. 

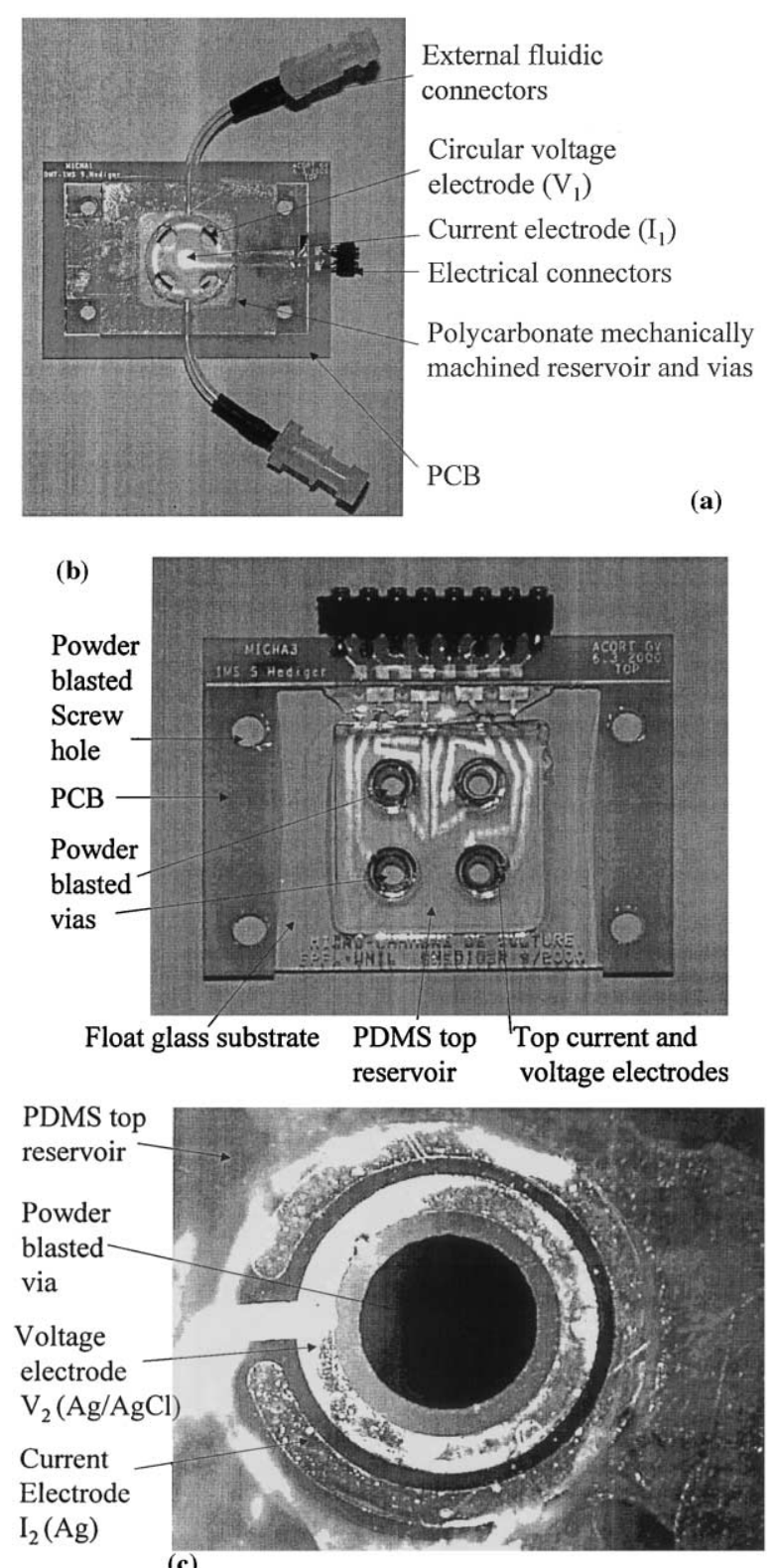

(c)

Fig. 4. (a) Optical photograph showing the finalised PCB mounted first level with external fluidic and electrical connectors, as well as the concentrical pairs of electrodes $\left(\mathrm{I}_{1}\right.$ et $\left.\mathrm{V}_{1}\right)$. (b) Optical photograph showing the finalised PCB mounted third level with external electrical connectors and top PDMS reservoir. (c) Optical photograph of the third level showing the concentrical pairs of electrodes $\left(\mathrm{I}_{2}\right.$ et $\left.\mathrm{V}_{2}\right)$ and the powder blasted via.

current electrode $\left(\mathrm{I}_{1}\right)$ and the concentrical lower voltage electrode $\left(V_{1}\right)$. The polycarbonate plate is manufactured in order to obtain a sufficiently large bottom fluidic reservoir in order to have enough physiological solution for the cells. The second level of the device is composed of two PDMS moulded layers with a nano-porous polycarbonate membrane glued in between. The diameter $\varnothing$ of a single culture site (determined by the free area of the membrane) is $1 \mathrm{~mm}$. The third level is similar to the first one with two concentrical electrodes $\left(I_{2}\right.$ and $\left.V_{2}\right)$ and vias. The basic structure of Fig. 1 is repeated to form four separate and identical cell culture wells on one modular tissue measurement device.

\section{Microfabrication technology}

Fig. 2 shows the batch process (represented for the basic structure of one culture site) for the realisation of the modular tissue culture device. Two lithographic masks, one metallic mask (for powder blasting) and three plastic moulding steps are used for the whole processing sequence. Two floatglass 4 " wafers are the substrates for the electrodes in the first and the third level. Wafer $n^{\circ} 1$ is $500 \mu \mathrm{m}$ thick, while wafer $\mathrm{n}^{\circ} 2$ is $2 \mathrm{~mm}$ thick in order to withstand the stress applied during the mounting of the complete structure. A lift-off photoresist step is used to pattern a $0.5 \mu \mathrm{m}$ deep recess in the glass wafers $\mathrm{n}^{\circ} 1$ and 2 by Hydrofluoric acid (HF) etching (Fig. $2 a$ and b), prior to the deposition of the $\mathrm{Ti} / \mathrm{Ag}$ film, in order to obtain recessed electrical contacts (Fig. 2c and d). This procedure gives rise to a flat wafer surface, which lends itself excellently for planar assembly with other layers within the stack. The hole structure of wafer $n^{\circ} 2$ in Fig. $2 \mathrm{e}$ is made by powder blasting through a metallic contact mask. Through-holes for the screw assembly step are powder blasted as well. Using a previously published gluing technology (Hediger et al., 2000), two moulded PDMS layers with vias are attached to the polycarbonate membrane, defining four different $1 \mathrm{~mm}^{2}$ culture sites per microsystem. A mechanically machined polycarbonate structure is glued on wafer $\mathrm{n}^{\circ} 1$, forming a lower reservoir and vias to the culturing membrane. The top reservoir is realised by combining the third level with a moulded PDMS part. The complete stack (Fig. 2f) is formed simply by mechanically pressing the three levels together, thereby using the elastic properties of the PDMS to have a microfluidic seal. The stack can be separated after culture and electrical characterisation to enable optical investigation of the cell layer using only the second level. The final step before use is the chlorination of the voltage electrodes $\left(\mathrm{V}_{1}\right.$ and $\left.\mathrm{V}_{2}\right)$. We use a galvanostatic growth of a $\mathrm{AgCl}$ layer on $\mathrm{Ag}$ in a $\mathrm{NaCl} 1 \mathrm{M}$ solution and using a Pt counter electrode. The current density used is 0.5 $\mu \mathrm{A} / \mathrm{cm}^{2}$ for a period of $10 \mathrm{~s}$ for chlorination of about $50 \%$ of the $300 \mathrm{~nm}$ thick Ag film, resulting in electrodes with a good open voltage stability.

\section{Results and discussion}

Fig. 3 is an optical photograph mounting, showing schematically the different levels of the modular tissue culture device. The structures of levels 1 and 3 are to be cleaned for each cell culture experiment and are re-usable; level 2, the PDMS sandwiched membrane, is to be changed for each new experiment. The three levels of the 


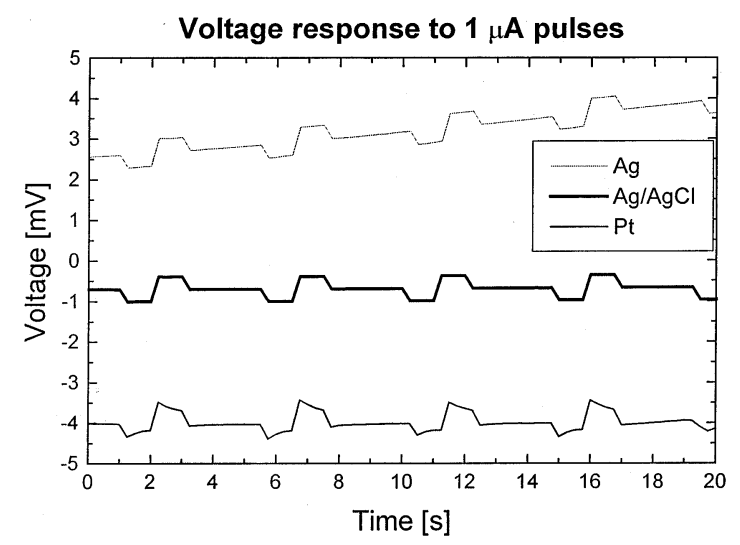

Fig. 5. Voltage response to $\pm 1 \mu \mathrm{A}$ and $1 \mathrm{~s}$ current pulses for three different electrode materials.

structure are mounted on an Al base using four nuts. Fig. $4 \mathrm{a}$ and $\mathrm{b}$ are optical photographs of the finalised first and third level, respectively, mounted on a printed circuit board (PCB), showing the outward electrical connectors, as well as the two fluidic connections to the lower channel. Fig. 4c is an optical photograph of the third level, where a powder blasted via and the concentrical top current and voltage electrodes can be seen.

Before cell culture, we have electrically characterised our microsystems. Fig. 5 shows the voltage response to $\pm 1 \mu \mathrm{A}$ and $1 \mathrm{~s}$ controlled input current pulses for three different electrode materials in a test device filled with a $\mathrm{NaCl} 0.1 \mathrm{M}$ solution. The application of such current pattern is standard for the measurements of the transepithelial resistance and transepithelial voltage for the cell layers grown in our device. One can observe the better stability of $\mathrm{Ag} / \mathrm{AgCl}$ electrodes compared to $\mathrm{Ag}$ and Pt electrodes (Grimmes and Martinsen, 2000). As we want the voltage changes in a real cell experiment to be a response to transepithelial currents (Ite) flowing through the cell membrane, one can easily understand the preferred choice of $\mathrm{Ag} / \mathrm{AgCl}$ as an electrode material. Fig. 6a shows the transepithelial resistance (Rte) evolution of three culture sites seeded with mCCD cells (cortical collecting tact cells) of transgenic mice in a standard mammalian physiological solution (Hummler et al., 1997). The resistance increases gradually until the 7 th day, when $10 \mathrm{mM}$ of amiloride (A) is added to each site. This product is meant to block temporarily the active transport of $\mathrm{Na}^{+}$and then has to be rinsed before continuation of further cell growth. Amiloride does not affect the Rte, as expected. The resistance is then quite stable until the 10th day when $10 \mathrm{mM}$ more amiloride is added again to each culture site. The resistance drops after one more day in the incubator (probably due to bad rinsing of amiloride). Fig. 6b shows the transepithelial voltage (Vte) evolution for the same experiment as for Fig. 6a. Vte is the voltage induced in the device by the transepithelial current (Ite), which has its origin in the spontaneous transport of ions through the cell layer. This voltage strongly increases after the 4th day of culture, when a considerable number of epithelial cells have grown on the polycarbonate membrane; these cells are characterised by an active $\mathrm{Na}^{+}$transport, which is the origin for the measured potential difference across the membrane. The consequence of the amiloride addition to the cells after 7 and 10 days is a voltage drop which confirms the temporary suppression of transport through the cells, although we would expect a drop to initial voltage. The presence of $\mathrm{Cl}^{-}$ion transepithelial transport (not affected by amiloride) or the drift of the open voltage potential of the $\mathrm{Ag} / \mathrm{AgCl}$ electrodes can be the origin of the relatively small decrease of Vte. Further cell cultures and characterisation experiments are being planned at the Institute of Pharmacology and toxicology at the University of Lausanne in the near future.
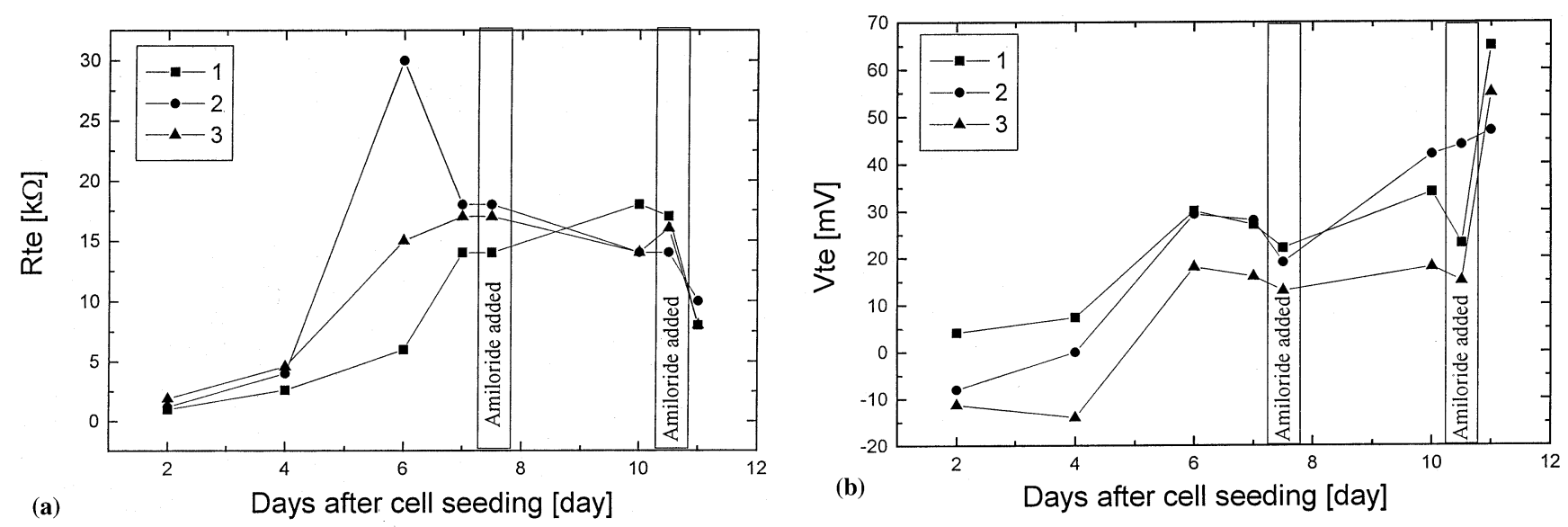

Fig. 6. (a) Transepithelial resistance (Rte) evolution of three culture sites seeded with mCCD cells. $10 \mathrm{mM}$ of amiloride (A) are added to each site after the 7th and 10th day. (b) Transepithelial voltage (Vte) evolution of three culture sites seeded with mCCD cells. $10 \mathrm{mM}$ of amiloride (A) are added to each site after the 7 th and 10 th day. 


\section{Conclusions}

We have designed and realised a microsystem for the electrical characterisation of epithelial cell layers for biomedical diagnostic purposes. We have used several fabrication technologies such as photolithography, wet etching procedures and powder-blasting, as well as metal thin film deposition and galvanostatic deposition in order to obtain micro-fluidic channels in glass substrates, with integrated patterned electrodes. Using a well studied gluing procedure (Hediger et al., 2000), we have realised a modular device for easy changing of the cell culture membrane. Finally we have demonstrated scarce mCCD epithelial cell layer growth on a miniaturised culture area $\left(1 \mathrm{~mm}^{2}\right)$ within our microsystem and have performed transepithelial resistance and voltage measurements of the cell mono-layer. We hope that our device will open new perspectives both for fundamental research and cell based diagnostic applications.

\section{Acknowledgements}

We would like to thank Prof. W. Hunziker of the Institute of Biochemistry, University of Lausanne (UNIL), Switzerland, for initial collaboration and stimulating discussions.

\section{References}

Belloy, E., Sayah, A., Gijs, M.A.M., 2000a. Powder blasting for three dimensional microstructuring of glass. Sens. Actuators A 86, 231-237.

Belloy, E., Thurre, S., Walckiers, E., Sayah, A., Gijs, M.A.M., 2000 b. The introduction of powder blasting for sensor and microsystem applications. Sens. Actuators A 84, 330-337.

Corning Costar $^{\circledR}$ product literature, 1999. Corning Costar Corporation, Acton, MA, USA.

Ehret, R., Baumann, W., Brischwein, M., Schwinde, A., Wolf, B., 1998. On-line control of cellular adhesion with impedance measurements using interdigitated electrode structures. Med. Biol. Eng. Comput. 36, 365-369.

Falcon ${ }^{\mathbb{B}}$ product literature, 1998. Becton Dickinson, Franklin Lakes, NJ, USA.

Fuhr, G., 1996. Examples of three-dimensional microstructures for handling and investigation of adherently growing cells and submicron particles, Analyt. Methods and Instrumentation, Special Issue $\mu$ TAS '96, pp. 39-54.

Fuhr, G., Shirley, S.G., 1995. Cell handling and characterisation using micron and submicron electrode arrays. J. Micromech. Microeng. 5, 77-85.

Grimmes, S., Martinsen, Ø.G., 2000. Bioimpedance and Bioelectricity. Academic Press, San Diego.

Hediger, S., Sayah, A., Gijs, M.A.M., 1999. Fabrication of a novel microsystem for the electrical characterisation of cell arrays. Sens. Actuators B 56, 175-180.

Hediger, S., Fontannaz, J., Sayah, A., Hunziker, W., Gijs, M.A.M., 2000. Biosystem for the culture and characterisation of epithelial cell tissues. Sens. Actuators B 63, 63-73.
Hummler, E., Barker, P., Talbot, C., Wang, Q., Verdumo, C., Grubb, B., Gatzy, J., Burnier, M., Horisberger, J.-D., Beermann, F., Boucher, R., Rossier, B.C., 1997. A mouse model for the renal salt-wasting syndrome pseudohypoaldosteronism. Proc. Natl. Acad. Sci. USA 94, 11710-11715.

Mall, M., Wissner, A., Seydewitz, H.H., Kuehr, J., Brandis, M., Greger, R., Kunzelmann, K., 2000. Defective cholinergic $\mathrm{Cl}(-)$ secretion and detection of $\mathrm{K}(+)$ secretion in rectal biopsies from cystic fibrosis patients. Am. J. Physiol. Gastrointest. Liver Physiol. 278, 617-624.

Milks, L.C., Brontoli, M.J., Cramer, E.B., 1983. Epithelial permeability and the transepithelial migration of human neutrophils. J. Cell Biol. 96, 1241-1247.

Misfeldt, D.S., Hammamoto, S.T., Pitelka, D.R., 1976. Transepithelial transport in cell culture. Proc. Natl. Acad. Sci. USA 73, 1212-1216.

Standen, N.B., Gray, P.T.A., Whitaker, M.J. (Eds.), 1987. Microelectrode Techniques. The Company of Biologists Ltd., Cambridge.

Wolf, B., Brischwein, M., Baumann, W., Ehret, R., Kraus, M., 1998. Monitoring of cellular signalling and metabolism with modular sensor-technique: the PhysioControl-Microsystem $\left(\mathrm{PCM}^{\circledR}\right)$. Biosens. Bioelectron. 13, 501-509.

\section{Biographies}

Serge Hediger was born in Vevey, Switzerland, in 1973. He received his degree in microengineering from the Swiss Federal Institute of Technology Lausanne (EPFL), after a diploma project carried out in the Ceramics Institute in the field of piezoelectric accelerometers in March 1997. He joined in April 1998 the Institute of Microsystems as research assistant in the field of new microsystems technologies for biomedical applications, in particular for living cell electrical measurement devices.

Abdeljalil Sayah received his degree in physics in 1988 from the University Mohammed V, Rabat, specialising in solid state physics. He obtained his AESA and DEA in microelectronics specialising in components technology in 1990 and 1992, respectively. From 1993 until 1996 he worked as a research assistant in the CNETBagneux Laboratory (Paris) where he received a Ph.D. degree for the thesis entitled "Realisation of Siliconbased dielectrics Optical Waveguide on InP by Photochemical Deposition". In 1996, he joined the Applied Optics Institute of the Swiss Federal Institute of Technology Lausanne (EPFL) as a postdoctoral researcher. His research interests included the study and characterisation of optical fiber tips for scanning near field optical microscopy by protection layer liquid-phase etching and characterisation of Bragg gratings produced on optical fibers by UV lasers. He is now with the Institute for Microsystems at EPFL. His current research interests include inertial sensors (gyroscopes), bio-sensors, and fabrication technologies. 
Jean-Daniel Horisberger received his degree in Medicine from the University of Lausanne (Switzerland) in 1977 and a Board certified by the Swiss Medical Society (FMH) in internal medicine in 1984. Subsequently, he carried out studies on Intracellular $\mathrm{Na}+$ and $\mathrm{K}+$ activities and membrane conductances in the collecting tubule of Amphiuma, as a post-doctoral fellow, at the Department of Physiology, Yale University School of Medicine, New Haven, USA, (Prof. G. Giebisch). He joined the Institute of Pharmacology and Toxicology, University of Lausanne (Switzerland) in 1988 as an assistant professor and then as associate professor in 1992. His research focuses on sodium and potassium transport through epithelial cells.

Martin A.M. Gijs received his degree in physics in 1981 from the Katholieke Universiteit Leuven, Belgium and his $\mathrm{Ph} . \mathrm{D}$. degree in physics at the same university in 1986. He joined the Philips Research Laboratories in
Eindhoven, The Netherlands, in 1987. Subsequently, he has worked there on micro-and nano-fabrication processes of high critical temperature superconducting Josephson and tunnel junctions, the microfabrication of microstructures in magnetic multilayers showing the giant magnetoresistance effect, the design and realisation of miniaturised motors for hard disk applications and the design and realisation of planar transformers for miniaturised power applications. He joined the Swiss Federal Institute of Technology Lausanne (Ecole Polytechnique Fédérale de Lausanne) in 1997 as a professor in the Institute of Microsystems of the Microengineering Department, where he is responsible for the Microsystems Technology group. His main interests are in developing technologies for novel inductive-type devices, new microfabrication technologies for microsystems fabrication in general and the development and use of microsystems technologies for biomedical applications in particular. 